\begin{abstract}
This month's News, Views and Comments column differs from those that have appeared in previous issues. The first of the companion papers presented here offers the first in-depth historical overview of Dr. Peter Neubauer's controversial study of infant identical twins separated at birth, launched in the 1950s. The author, Dr. Lawrence Perlman, was a research assistant on the project while earning his doctoral degree in clinical psychology from New York University. His paper is followed by my own critical appraisal of issues raised by that study, some of which are still timely today. Readers are invited to forward their comments to me (nsegal@fullerton.edu) for possible consideration in future columns of Twin Research and Human Genetics.
\end{abstract}

\title{
Memories of the Child Development Center Study of Adopted Monozygotic Twins Reared Apart: An Unfulfilled Promise
}

Lawrence M. Perlman

Department of Psychiatry, University of Michigan, United States of America

\section{Then}

The year was 1968 . I was a 24 -yearold doctoral student in clinical psychology at New York University (NYU), fresh out of my internship at the Veterans Administration Outpatient Department in Brooklyn. A fellow student told me about a part-time research position that was available at the Jewish Board of Guardians (JBG), assisting in a study of adopted twins reared apart. It sounded like a great opportunity to find a dissertation topic and finish my PhD. Many of my colleagues had clinical positions, but were stuck in the 'all-but-dissertation limbo'. I jumped at the chance to get my research started.

JBG had its main office on the upper floors of a building at 120 West 57th Street, in an upscale neighborhood down the block from Carnegie Hall. It had satellite clinics and residential treatment centers throughout the city. JBG was known as a good place to get clinical training in child therapy, even though the pay was poor. The Child Development Center (CDC) was housed in the main office. It was a research enterprise that also provided therapeutic services for preschoolers and their parents. I recall there being a therapeutic nursery, modeled on Margaret Mahler's facility on the Upper West Side, and several ongoing research projects. One of them was a study of adopted identical twins, separated at birth and reared apart.

The twin study had been going on for several years by the time I arrived. It was the brainchild of Peter B. Neubauer, a prominent child psychiatrist who was the director of CDC. A psychiatric consultant named Viola Bernard, who I never met, was also a central figure. Neubauer was a psychoanalyst, as were most clinicians in New York in those days. He was a busy man, who seemed to have little day-to-day input into the research. My boss, a psychologist named Nancy Edwards, was the project director. She was a young graduate of Columbia University with a background in child development, who was also in psychoanalytic training in NYU's postdoctoral program. I do not recall whether there were any other personnel on the research team.

The study was unique. Louise Wise Services, a well-known Jewish adoption agency, was separating infant identical co-twins and placing them in carefully selected families that were matched according to parents' ages, socioeconomic status, educational level and religion, and older siblings' gender and age. The siblings had also been adopted through the Louise Wise agency, so the families were well-known return customers. This time, the parents were told that they and their children were part of an ongoing study of child development that would require annual home visits and psychological testing. They were never informed of the twinship status of their new adoptee.

(There may have been exceptions to the family selection practice. In the only published report of the study, Abrams [1986] indicated that the adoptive parents of one female twin had a biological son, and that her twin was adopted by a family with two children, a son and a daughter. In addition, these two families differed somewhat in socioeconomic level.)

Suppression of the twinship information is a crucial issue that has become a point of contention with regard to the ethics of the research. In fact, it was one of the things that Dr. Nancy Segal asked me about when we

Address for correspondence: Lawrence Perlman, PhD, VA Ann Arbor Healthcare System, 2215 Fuller Rd. (116C), Ann Arbor, MI 48105, USA.E-mail:Iperlman@umich.edu 
met in December 2004. How could this information have been kept from the parents? Weren't they entitled to know that their children were twins? Of course, a major premise of the research was that they not know. The twin study staff believed that a weakness of prior studies on twins reared apart was the twins' and parents' knowledge that there was an identical sibling out there somewhere. It was assumed that such knowledge could affect the handling of the child by the parents, as well as the child's own sense of self. This study intended to eliminate such confounding variables.

The principal virtue of the study was that it was prospective and longitudinal. We had the unique opportunity to build on an experiment of nature: to follow two individuals with identical genetic makeups from birth throughout their developmental years. We would be able to study their families, as well, in order to focus on differences in parenting styles that might affect their psychological characteristics.

All prior research on twins reared apart had consisted of retrospective studies of pairs that were reunited later in life. We believed that many had discovered one another by virtue of institutionalization or problems with the law, introducing sampling errors from which our study was immune. (However, later research demonstrated that most reunited twins had not met because of deviant behaviors.) Our data were much richer and more representative because we were observing the twins (and their families) from infancy. Since we had controlled for key differences in the families' environments, we would be able to tease out subtle differences in the twins' personalities and lifestyles. Thus, we believed that the findings would have greater generalizability than previous ones.

The one variable for which we could not control was the fact that these youngsters were adopted. This implied that the parents had experienced infertility problems and associated psychological and social challenges in their quest for children. In addition, the twins were likely to have had biological mothers who were young, unwed and promiscuous, which could have implications regarding the children's genetic endowments, for example, the youngsters might be impulsive or overly active.

Much to my dismay, I soon discovered that the research, while well conducted, was not well organized. Data had been collected for several years, but no-one had begun to properly compile and analyze it. Dr. Neubauer was a remote figure with whom I seldom interacted. (Abrams [1986] reported that there were weekly staff meetings. If so, they may have occurred on a day that I did not work at CDC.) Neubauer was a child psychiatrist and respected clinician, but was unfamiliar with research design. My boss, Nancy Edwards, did not seem to be especially invested in the research. It soon became apparent that, unassisted, I would need to carve out my dissertation research from this mass of data.

I set to work learning about twins. I became familiar with gestation, birth, infant testing, and other child development topics that were missing from my graduate studies. I had soon compiled a comprehensive bibliography on twins reared apart and had read all the extant studies. I clarified the research questions and identified some of the crucial variables.

At that point, it became clear to me that one of the most essential pieces of data had never been addressed, namely proof of the twins' monozygosity. While we had lots of information on the infants from their moment of birth, such as Apgar scores, it was often not possible to determine if there had been one or two placentae. Furthermore, no one had compiled the available data on blood types that could establish their likelihood of being identical twins. Since DNA testing was years away, it was only possible to demonstrate with a certain degree of probability that a given pair was identical; one could never be $100 \%$ sure. Yet, incredibly, no one had bothered to calculate these values. There was not even a database for this information; it was buried in hospital records that had been provided to us.
Dr. Segal commented that it would not have been such a hard task to make those calculations. Now it is not, but in 1968 there were no desktop computers, no canned statistical programs. We had to compute $t$ tests and other statistical analyses on cumbersome calculating machines. To use an enormous IBM computer for data analysis meant getting special training, hiring a consultant, having handwritten data converted to punch cards, and running a program that was certain to fail the first few times. Without funds to hire clerical workers, one had to spend hours recording and compiling data by hand.

As for the ethics of the research, I do not recall a single discussion of whether or not it was inappropriate to conceal the knowledge of twinship from the families. Again, it is important to put oneself back in the 1960s. Informed consent for research subjects was not a required practice. Of course, the dictum to respect subjects and not do psychological damage was very much a part of our ethos. No one suspected that we were doing otherwise. Our principal responsibility was to maintain confidentiality about the twins and their families.

Adoption records were sealed and inviolable. Parents who adopted babies did not expect to learn anything about the infant's biological mother or father. In fact, most had no interest in being burdened by that knowledge. Environmental influences on development were assumed to be paramount. It was accepted that these children would have better lives than could have been possible with their generally unwed, teenage parents. Young, pregnant women were frequently sent away to secretly give birth and then give up their babies for adoption. Their sexual promiscuity was condemned by their own families. Some female patients that I treated in my later clinical work had endured such an ordeal and had been emotionally scarred by it.

Thus, the adoptive parents, entering into a contract with the Louise Wise Services, were guaranteed that they would not know anything about the family background of their infants, including the possible exis- 
tence of biological siblings. No-one expected anything else. It was the obligation of the research team to preserve this confidentiality, and we were keenly aware of that responsibility. It was essential that we not reveal to the families even a hint that our study was about twins. Looking back at the research from the perspective of 2005 , it seems odd that we did not anticipate the likelihood of these children meeting one another by chance at some future time. After all, they were placed in families of like socioeconomic status and religion in the greater New York metropolitan area. But again, it is important to recognize the changes that have occurred in American society in the past four decades. Communities were more separated and insulated in those days; it was a bigger world. People did not travel as widely or as frequently, and instantaneous communication of information was a dream. Apparently no-one had considered what now seem to have been critical oversights in the study: the twins rights to know each other and the possibility that they might meet in the future.

The notion that these individuals might some day be entitled to know about the existence of their twins was never discussed during my year (1968 to 1969) on the research team. Perhaps such questions had been debated by the architects of the study in its early years, but we were certainly not privy to such discussions. There was no end plan for debriefing the subjects somewhere down the line; there seemed to be no need for one.

The significance of a person's genetic endowment for behavior did not loom large in the 1960s, as it does today. The idea of an adopted child searching for his or her biological family was not in fashion. Certainly, some adoptees had such an interest and embarked on the quest. But state adoption laws and agency policies posed formidable barriers. It was some years before registries were set up to reunite adult adopted children with their birth parents, provided that both were willing.

The children in the twin study were followed from birth. I recall a visit to a pair of 28-day-old twin girls who were in foster care, awaiting placement. We observed and rated them, using infant scales such as the Cattell and the Bayley. We also interviewed the foster mother, who was an experienced observer in her own right, having raised six children and fostered many babies.

The data on the twins after adoption were collected at periodic visits to their homes, every 3 months for the first year, every 6 months for the next 2 years, and annually thereafter. A filmed sample of their play activity was made, an interview was conducted with the mother, and an IQ test was administered to the twin. The visits were scheduled 1 week apart, so that the observations would be made at the same developmental moment and by the same staff members. We worked as a team, one examiner interviewing the mother while the other worked with the child. Having been trained in psychometrics, I did the testing and wrote the reports. These evaluations included qualitative observations, as well as IQ scores. I recall, in particular, two 7-year-old boy twins who were thrilled to have a male examiner. Apparently, all of their previous visits had been made by women.

The families were not simply observed as guinea pigs. If they expressed the need for guidance in dealing with their children, they were offered access to counseling services at CDC. Thus, an unspoken goal of the project was to insure that the youngsters were receiving optimal parenting.

We were not concerned about experimenter bias in having one psychologist test both twins. In fact, we thought it was preferable to having two testers, because another source of variance could be eliminated. The work on researcher expectancy effects was just coming out in those days and did not seem relevant to our study. However, it is possible that the observer's preconceptions colored our characterizations of the twins.

An elaborate coding system for the films was being developed, based on similar studies by psychiatrists Stella Chess and Alexander Thomas, and their collaborator Herbert Birch, and by Sibylle Escalona. These people were also in New York, doing psychoanalytically based child development research. This work was influenced by ego psychology and object relations theory. The goal was to identify the characteristic patterns individuals used to neutralize impulses and adapt to their environments. Sensory-motor reactivity, motility, affect, object relations, adaptability and a host of other dimensions were rated.

The visits and the IQ data were an eye opener for me. I had subscribed to an interactionist position regarding the nature-nurture debate, but was still somewhat of an environmentalist. These identical reared-apart twins were remarkably alike! Knowing that they and their families hadn't the slightest inkling about one another, it was striking to see how similar their behavioral characteristics and IQ profiles were. I became convinced of the primacy of one's genetic endowment, mutable though it may be by environmental influences.

I proceeded to work up the longitudinal IQ data for analysis and, hopefully, a dissertation. But the job became too overwhelming because there was no support or guidance for my work. I also came to realize that the inner workings of the study were shaky. My task began to seem more like just a job and less like a pathway to my $\mathrm{PhD}$. So, when a friend asked me to take over his position at Maimonides Medical Center for a year, I decided it was time to leave. I gave notice to Nancy Edwards and then to Dr. Neubauer. Oddly enough, Neubauer was reluctant to see me go, even though we had spoken little during my tenure there. Apparently, he recognized that there was some potential to my work. He even hinted at a higher salary, but my mind was made up.

\section{Now}

Over the years, I often wondered about the study, but I had lost contact with the other staff members. I assumed that a report of such a significant piece of research would appear in the professional press. It was years later, in 2001, that I met Dr. Thomas J. Bouchard, Jr., director of the well-known study of twins reared apart at the University of Minnesota 
- he was giving a lecture at the University of Michigan soon after my arrival there. Had he heard of the CDC research? Certainly he had. It was infamous! There had been an exposé in the popular media after a set of identical triplets had been reunited by chance (Associated Press, 1980; Cummings, 1980; Cummings \& Krebs, 1980). Lawsuits had been threatened against the Louise Wise Services, JBG, and the major participants (Saul, 1997). Everyone had hunkered down and gone underground. The fate of the data? That was a mystery.

Bouchard put me in touch with Dr. Nancy Segal, who had written a book, Entwined Lives (Segal, 2000), which referred to Neubauer's study in one of the chapters. We corresponded sporadically until meeting in New York in December 2004. Shortly before that, I had attempted to contact Nancy Edwards, only to discover that she had died several months earlier. At that time, an exhibit of Viola Bernard's archives was underway at the Columbia University Health Sciences Library. Nancy Segal and I hoped to glean more information about the origins of the study that might answer some of our questions. We visited the library, but discovered that all correspondence and records of meetings regarding the study are sealed until January 1, 2021. We found the following reference to the project in an online biographical note <http://library.cpmc. columbia.edu/hsl/archives/findingaids/bernard.html>.

'Bernard was co-investigator with Peter Neubauer in this longitudinal prospective research project about identical twins placed as infants in separate adoptive homes and reared apart. Bernard wrote in 1963 that the study 'provides a natural laboratory situation for studying certain questions with respect to the naturenurture issue and of family dynamic interactions in relation to personality development'. The study later aroused controversy, chiefly because the adoptive parents and adoptees were not informed about the twinship, in keeping with the practice of the day.'

Having heard from Dr. Segal that Peter Neubauer was still alive, I phoned him. I was surprised to learn that he continued to maintain a clinical practice and an active professional life. He did not remember me by name, but was willing to grant an interview to Dr. Segal and me before we left town.

We met with Dr. Neubauer on December 27, 2004, in his elegant Upper East Side office, furnished with antique furniture and archeological artifacts. At 91 years of age, he is remarkably fit, alert, intelligent, and incisive. He was gracious and charming to a fault. Dr. Neubauer responded to a number of our questions regarding the origins of the study and details about its execution.

It was apparently during a casual conversation with Viola Bernard that he discovered that identical twins were being placed in separate families. Bernard was chief psychiatric consultant to the Louise Wise Services and a close friend of Judge Justine Wise Polier, who was a board member and daughter of the founder. (In her biographical note, Bernard is credited with having professionalized the agency. 'She developed a credentialed professional staff, solicited government funding, and established procedural structure and accountability at an organization which had previously operated in a relatively adhoc, informal manner.') It was Dr. Bernard's belief that being a twin was a handicap because it prevented a child from securing a special place in the family. Given that the twins were being put up for adoption, it would be in their best interests to be reared apart as separate individuals. In order to relieve them of the burden of knowing that a twin existed and, thus, eliminate the wish to search for that sibling, the families were not informed of the existence of a twin sibling.

Realizing that this was a unique research opportunity, Neubauer created the framework for a research study. Private funding was secured from an anonymous donor, who was a twin. (In a footnote, Abrams [1986] cited the support for the project as coming from the Philip and Lynn Strauss Philanthropic Fund and the Tappanz Foundation, later renamed the Viola Bernard Foundation! Saul [1997] reported that the study was also partly funded by the National
Institute of Mental Health.) There was apparently no thought of informed consent, since the parents were to be kept in the dark regarding the twinship status of their adoptees. Although Neubauer stated that it was 'the belief of the time' that being a twin was handicapping, his efforts to enlist a Catholic adoption agency to participate in the study were thwarted by the director (ironically named Sister Bernard), who categorically stated that what God had created should not be torn asunder.

In total, 13 adopting families were enrolled in the study, comprised of five twin pairs and one triplet set. I believe that one of the triplets had dropped out of the study by the time I arrived because I only tested two of them. It is not clear whether any other families left the study prematurely. The intention was to follow the families until the youngsters reached puberty, this apparently having been viewed as the critical period for psychological development.

The researchers were interested in identifying personality traits, such as sensitivity to the environment, which might have quite different behavioral manifestations in each twin. Thus, the superficial presentations might differ, but the underlying temperamental dimensions would be identical. Neubauer considered these differences to be even more interesting phenomena than some of the striking similarities in personal preferences that were observed.

The latter could result in unusual contrasts in parental reactions. For instance, one pair of identical girls had each exhibited a strong preference for catsup at about 2 years of age. One mother was frustrated by this and continually endeavored to change her daughter's taste preference, while the other gloried in how easy it was to feed her daughter, since she only needed to pour a liberal amount of catsup on any type of food. (This story is reported in Neubauer and Neubauer [1990, p. 20], with the preference being for cinnamon.)

When the press got wind of the study after the chance meeting of a twin pair some 15 years or so into the research, Neubauer was approached by Walter Cronkite about a proposed 
TV report (Neubauer was apparently referring to the reuniting of the triplets in 1980). He convinced Cronkite to drop the story, because it would be psychologically damaging to the remaining twins to have their identities revealed. Subsequently, Neubauer had to fend off an even more determined effort by a host of 60 Minutes. However, much to his dismay, the story continued to appear in the press (Saul, 1997), and he was mercilessly questioned regarding the ethical questions posed by concealing the twinship status of the adoptees.

Neubauer continues to maintain that everything done in the study was proper, and that it conformed to the adoption practices and research standards of the time. He stated that the data had been deposited at the Yale University, with the proviso that they remain sealed until the year 2021 .

I left the meeting impressed by Neubauer's intellect and professional dedication. Likewise, it is difficult to read Viola Bernard's resume without being struck by the fact that she was a dynamic and creative psychiatrist, who was involved in truly innovative projects dedicated to the common good. Yet, both of these prominent psychiatrists were blind to the potential ethical issues posed by separating these twins and maintaining secrecy about their twinship for so many years.

Dr. Segal informed me that two sets of identical twins had been reunited, in addition to the triplets. It is not clear why the data on these six individuals needs to remain sealed for 15 more years, since the confidentiality requirement no longer seems relevant. (One triplet committed suicide in 1995.) All of these individuals are now adults and are aware of the circumstances of their separation and adoption. The fate of the other three pairs of twins is unknown.

So little has been published from the wealth of material collected on these 13 individuals. Neubauer gave me a copy of the book he published 15 years ago with his son, Alexander, who is a writer (Neubauer \& Neubauer, 1990). It alludes to the twin study in several places and provides tidbits of information relevant to the similarities in personality and preferences of several twin pairs. One wonders if it still might be worthwhile to track them down, invite those twins who had not yet found one another to reunite, and collect follow-up data.

\section{Postscript}

While preparing this article, I attempted to locate the data and to ascertain the nature of the agreement according to which it had been ceded to Yale. I first spoke with the current director of CDC, Marian DavidsonAmodeo, CSW. She has worked there since 1975 and became administrator in 1984 at the time of Neubauer's retirement. She has been director since 1990. Ms. Davidson was aware of the twin study, but had never worked on it and had no idea what happened to the data. She implied that it was Dr. Neubauer's private project. When I said that surely there must be some records of where the data were sent, she indicated that there were none. She was cordial, but not eager to discuss the project.

I also managed to speak with Dr. Christa Balzert, who was cited by Saul (1997) as having been one of the lead psychologists on the study. She apparently was hired about a year after I left CDC and remained there through the mid-1970s. She had other responsibilities at CDC and only worked peripherally on the study, interpreting some of the test data. She reported not having actually interviewed the youngsters. When asked why nothing was ever published, she cited concerns about confidentiality. She agreed that 'the study had disappeared from the face of the earth'. Dr. Balzert also recalled participating in staff meetings 'every so often'. She had no idea when the study was terminated or how many subjects had dropped out. She remains on cordial terms with Dr. Neubauer and sees him at professional meetings.

Seeking the location of the data, I made inquiries with the head archivist of the Yale University Library. After some investigation, he wrote that there was no record of files from CDC or JBG having been deposited at Yale. The only reference to Dr. Neubauer was some correspondence between him and Dr. Donald Cohen of the Yale Child Study Center.
I phoned Neubauer for clarification. On January 31, 2005, he returned my call but declined to answer the question, only asking why I wanted to know the location of the data. I explained that I was writing a remembrance of the study. He stated that he had no time to talk, would need to call me back, and abruptly hung up. Thus far, I have not received a response to the call or a follow-up email inquiry.

Subsequently, the archivist at Yale did locate the files, listed as Manuscript Group 1585. They were gifted to Yale in 1990 with the proviso that the records remain sealed until 2066! I was told that Yale is not permitted to publicize the conditions of the deed of gift. The records can be accessed by researchers who receive written authorization from the executive vice president of the Jewish Board of Family and Children's Services (currently Dr. Alan Siskind). Curiously, the inventory lists records on only 11 children. The data comprise 67 linear feet and include reports of home visits, test data, longitudinal profiles, developmental sequences, films, tapes, progress reports, a statistical study with the name Adler on it, minutes of meetings, and so forth (Staff of manuscripts and archives, 2004). Thus, this rich trove of data may now be accessible to qualified researchers and, probably, to the twins themselves if they wish to reconstruct their pasts. 


\section{Commentary: More Thoughts on the Child Development Center Twin Study}

\author{
Nancy L. Segal \\ Department of Psychology, California State University, United States of America
}

The editor, Nick Martin, congratulates Nancy Segal on being recognized as the 2004-5 Outstanding Professor of the Year at California State University, Fullerton.

\section{Introduction}

It is a study that will not go away.

It was fall 1982 when I arrived at the University of Minnesota as a new postdoctoral fellow, to work on the Minnesota Study of Twins Reared Apart (MSTRA). By then, the MSTRA had gained considerable stature, drawing attention from national and international scholars and journalists. But for a brief time during my early years in Minnesota, an older twin study was becoming newsworthy once again. CBS's news magazine, Sixty Minutes, was preparing an exposé of Dr. Peter Neubauer's 1950s Child Development Center (CDC) twin project. The program intended to show how and why a group of New York child psychiatrists and psychologists decided to 'play God', separating infant twins and tracking their development without informing the twins' adoptive families that their children were twins. The investigative journalists also wanted to know what the scientists hoped to learn from this unique study, the only one in the world to follow separated twins prospectively from birth. Ultimately, the planned television special was cancelled for reasons I would later learn. But some scientists and journalists still revisit this controversial study from time to time. It is a study that will not go away.

The project, described in detail for the first time by Dr. Lawrence Perlman, had a fairly innocuous start. In the early 1950s, Columbia University child psychiatrist, Viola Bernard, was an advisor to the Louise Wise Adoption Services in New York City. Bernard believed that monozygotic (MZ) twins growing up together suffered from never securing a special niche in their family. Consequently, when unwed mothers relinquished their infant twins and triplets for adoption, Bernard advised the agency staff to place the babies in separate homes. Once this policy was in place, Bernard mentioned the separated twins to her friend and colleague, Dr. Peter Neubauer. He replied, 'They must be studied'.

The opportunity to study separated identical infant twins perfectly matched the interests of Neubauer and his colleagues. They wanted to determine how subtle parenting differences predicted child behaviors. They also wanted to know what constituted an optimal fit between adoptive parents and their children. Neubauer took pride in the fact that once the adoption agency identified mothers pregnant with twins, his team 'was there at the birth'.

\section{Looking Back}

The sequence of events leading to the research resolves a crucial point of contention among individuals familiar with the study, namely whether or not the twins were intentionally separated for research purposes. It seems that they were not. However, the decision to separate the twins created an ideal condition for prospectively investigating genetic and environmental influences on physical and behavioral characteristics and predispositions. Until the CDC study was conducted (beginning in the early 1950s and continuing through the mid-1970s), reared-apart twin studies were retrospective, relying on the recollections of adult twins, mostly without the observations and insights of their rearing parents (see, for example, Newman et al., 1937; Shields, 1962; Juel-Nielsen, 1966).
I suspect that the two processes (separating twins and studying them) perpetuated one other - as the research benefits of separating twins became clear, efforts to find additional cases intensified. As Dr. Perlman indicated, Neubauer had contacted Sister Bernard at Catholic Charities in New York hoping to identify other separated sets. She would not cooperate at first, arguing that what had been put together naturally (twins) should not be split apart. Neubauer replied that mothers and children (who are also put together naturally) can be separated via adoption. He said that Sister Bernard eventually agreed to help him, although she never furnished the promised pairs. The final CDC twin sample included five $M Z$ twin pairs and one $M Z$ triplet set, all placed through the Louise Wise Agency. Thirteen children and 13 families were involved.

Like my twin research colleagues, I always wondered about the origins, progress and ultimate fate of the Child Development Center twin study. It was curious, as well as troubling, that quantitative analyses of the data never appeared in the psychological literature. The few descriptive accounts include a 1986 case study of a single twin pair (Abrams, 1986), and a book by Neubauer and his journalist son, Alexander (1990); unfortunately, the book provides little information beyond the earlier case report. Then, a number of years ago I came across two references to a

Address for correspondence: Nancy L. Segal, Department of Psychology, California State University, Fullerton, CA 92834, USA. E-mail: nsegal@fullerton.edu 
reared-apart $\mathrm{MZ}$ female twin pair the first one was in a 1977 book by New York child psychiatrists, Alexander Thomas and Stella Chess. The reference had a bibliographical note that a more detailed paper by Chess, Ladimer and Thomas was in progress. The second one was in a 1986 chapter on temperament by behavioral geneticists, Ronald Wilson and Adam Matheny (1986), who cited that chapter. Knowing that Neubauer, Chess and Thomas shared professional interests and worked in New York, I assumed that the twin pair in question was 'borrowed' from Neubauer's study, or at least identified through the Louise Wise Agency. I was wrong, as I will explain.

Probably the most important issue concerning researchers and members of the media was that the adoptive families were not told of their children's twinship status. Such information would not be withheld from adoptive parents today for numerous ethical reasons. I now understand why Neubauer and his staff kept this knowledge concealed, but I do not condone it. To fully understand how it happened, it is necessary to consider their research decisions in the context of the times. Dr. Perlman explained this when I met him at Columbia University's Health Sciences Library in December 2004 - during the last days of the new Viola Bernard exhibit.

It was exciting - we had corresponded by telephone and e-mail several times since 2001, after Dr. Thomas J. Bouchard had put us in touch. But this was the first time we were in the same city. Once Dr. Perlman arrived, we talked for a long time. I was riveted by what he had to say - it was the first time I, or probably anyone outside the study, was learning about what actually took place. (Neither the husband or daughter of the now deceased Project Director Nancy Edwards knew much about the project when I contacted them.) As Dr. Perlman pointed out, in the 1950s adoptive children's biological backgrounds were not shared with their adoptive parents who, for the most part, were not interested and did not want to be burdened with this information. Furthermore, since the twinship status of the twins had been provided to the researchers in confidence, they were obligated to maintain silence on this point. The researchers also worried that if parents knew that their adoptive child was a twin then parenting practices and child outcomes would be affected precisely what the study was all about. The team also believed that the twin children would eventually want to seek each other out if they knew about the existence of their twin, something that would upset their adoptive families.

\section{Addressing the Issues}

I have known many reunited twins. I have witnessed their pleasure in finding each other and in getting to know one another (Segal, 2000; Segal et al., 2003). Not all twins have developed or maintained close relationships, but every twin was grateful for the opportunity to become acquainted and to learn more about his or her past. At the same time, bitterness, anger and regret were voiced by many. They were upset that decisions to separate them mainly benefited the families and agencies, with little or no regard for how separation might affect them over the years. (For example, if families could not afford to raise two children at the same time, it was easier for agencies to place one child, rather than wait for a family willing to take two.) Sorrow over the lost opportunity to share their childhood years was also a frequent theme, as was disappointment that their own children had never known their aunts and uncles.

Despite the climate of the times regarding adoption practices, it appears that Neubauer failed to see the big picture. An investigator in his position should have asked Bernard to justify her assertion that twins suffer significantly from growing up together. But does such literature exist? Other than individual reports of twins confronting identity and separation issues, I am unaware of formal studies supporting Bernard's view. Of course, little research attention was directed toward the nature and significance of sibling relations until the 1980s (National Adoption
Information Clearing House, 2004). Even less consideration was given to the behavioral consequences of placing siblings in separate adoptive and foster homes, although some early studies were available. Aldridge and Cautley (1976) found that common placement was viewed positively by foster parents in $27 \%$ of the cases, whereas it was viewed negatively in $25 \%$ of the cases. Social workers viewed common placement positively in $49 \%$ of those cases, whereas 35\% viewed it negatively. In the introduction to their 1992 study, Staff and Fein (1992) noted that investigators generally agreed that siblings should be placed together. They also noted that this policy is maintained by the Child Welfare League of America, as set forth in their 1989 standards.

One could imagine specific situations supporting separate placement of twins and siblings. In an unusual twin custody case I favored separating 8-year-old dizygotic (DZ) twin girls, one of whom was severely mentally retarded and physically handicapped - the special needs of the affected twin disrupted the activities, interests and welfare of her unaffected co-twin (Segal, 2000). Staff and Fein (1992) provide additional discussion of events that might or might not warrant separating siblings, some raised in the mid-1950s. Examples of events that might support separation include sibling interdependence and hostility, although researchers assign different levels of importance to such circumstances. Negative effects from rearing siblings separately include lack of companionship, lack of support, reduced self-esteem and increased depression (National Adoption Information Clearing House, 2004). The important point is that decisions regarding the placement of adoptive twins and siblings need to consider the individual circumstances of each set.

A recent article in Adoptive Families magazine questioned the wisdom of placing unrelated nearin-age siblings in the same home (Johnson, 1997). The arguments were that children do not secure special places in their family, parental resources are strained and children's 
best interests are neglected. These views seem to support Bernard's practices and beliefs, but they were not research-based. In fact, virtual twins (near-in-age unrelated siblings raised together from infancy) in my ongoing study have obtained IQ scores that were above average and behavior problem scores that were below those of children in clinical and nonclinical samples (Segal, 2000).

Most twins dealing with twinship issues do so successfully - in fact, it has been well established that twins are no more highly represented than nontwins among psychiatric and problem-behavior populations (Kendler et al., 1995; Moilanen et al., 1999; also see Segal, 2000). I suspect that Bernard's beliefs on separating twins were based on her own clinical impressions of selected twin pairs, and possibly those of her colleagues. If so, this would not provide sufficient reason to routinely separate the infant twins. In fact, given Bernard's reasoning, one could conclude that all twins (not just those given up for adoption) should be raised separately!

It is unclear to me how parents' knowledge of their child's twinship would affect parenting practices in significant ways. Some critics of reared-apart twin studies have asserted that certain features of the twins' rearing environments explain their degree of adult similarity, for example, being raised by biological relatives or having had frequent contact prior to assessment (Taylor, 1980). However, reanalyses of these findings have disproved these charges (Bouchard, 1983, 1997). In addition, most separated twins have enjoyed loving relationships with their adoptive families and have delayed searches for biological parents and siblings until adulthood so as not to hurt their families. Twins who have searched earlier have usually enjoyed their adoptive parents' support. Thus, there is little reason to believe that parents' knowledge of adoptive children's twinship would have proven detrimental to their wellbeing. If anything, it might have helped explain some of the twins' developmental features, such as their lower than average birth weight and more uncertain health status, relative to nontwins (Taffel, 1995).

\section{Further Comments}

Viola Bernard's extensive archive at the Columbia University Health Sciences Library (http://library.cpmc. columbia.edu/hsl/archives/pastacq. html) is open to the public, with the exception of documents and correspondence associated with twins and the Louise Wise Services. Most of this material has been sealed until 2021; interestingly, these files are dated 1953 to 1997 suggesting that Bernard's involvement in this work continued after the study ended in the mid-1970s. The actual twin data have been given to the Yale Child Study Center, in New Haven, with a similar stipulation - that they not be released until 2066; an inventory of items is available at http://mssa.library. yale.edu/findaids/stream.php?xmlfile= mssa.ms.1585.xml

Neubauer believes this is a good thing as it will protect the twins until they are well into adulthood. However, there are reasons to reconsider these decisions. The twins are now mature adults who are entitled to know about their past. Some events that may have been unclear and confusing to them could be clarified. And those twins who have not yet met (possibly three pairs) might benefit from the medical knowledge that their twin can provide, and from the close companionship they may offer to one another.

I wondered how Peter Neubauer and his staff might have felt if they had been among the separated twins. Would they have been angry if researchers had withheld this information from them? There was a lot I wanted to ask him. The opportunity to do so presented itself when Dr. Perlman arranged a meeting with Neubauer at his New York office, in December 2004.

Neubauer was a warm and gracious host, especially when he learned that one of my best high school friends was his younger cousin. He invited us into his study, a beautifully furnished room decorated with interesting artifacts he had acquired on his travels. He answered our questions openly and honestly, echoing the views of Viola Bernard. He remains convinced that separating the twins and studying them as he had done was correct. Amazing as it seems, he is apparently unaware of the twins' special situation, specifically how separating them, studying them, and concealing their twinship might have affected them in later years. Neubauer was still surprised that his work had come under attack from the media. Apparently, his personal contacts at CBS news had been sufficient to halt their investigation and the Sixty Minutes special.

Neubauer raised some question over whether the New York triplets, Bobby Shafran, David Kellman and Eddy Galland (who found each other at age 19; see Saul, 1997) were truly $\mathrm{MZ}$, because there were two placentas. I reminded him that onethird of $\mathrm{MZ}$ twins have separate placentas. Moreover, the triplets had been blood-tested at the University of Minnesota and were shown to be MZ. He remains unconvinced.

I asked Neubauer his opinion of recent twins-reared-apart studies, such as the one in Minnesota. 'It's a starting point', he said. He explained that genetics means much less at the individual level, where one can associate twin differences with parenting differences. I was reminded of Newman et al.'s (1937) finding that, despite genetic influence on IQ, more educationally advantaged twins outperformed their less educationally advantaged co-twins. However, this does not imply that genetics 'means less' - rather, the levels of analysis differ. Genes and environments are both important for human development, but their relative contribution can be estimated only at the group level. It is impossible to say which one has greater impact at the level of the single person.

Neubauer stood up after about 45 minutes, signaling that our meeting was over. (Knowing his psychoanalytic background, I was not surprised by the '50-minute hour' limit.) Before leaving, he and I exchanged books. I felt pleased to have met him and to have gained some knowledge of the inner workings of his study. But there was another person I wanted to talk to. It was Dr. Stella Chess, one of the principal investigators on the New York State Longitudinal Study (NYSLS) of temperament. As I 
indicated above, I wondered about the source of her one reared-apart $\mathrm{MZ}$ twin pair. I called her and we arranged to meet at her home in January 2005.

Dr. Chess, an elegant 90-year-old, greeted me warmly. It was exhilarating to meet someone whose work with childhood temperament was so well known. To her credit, she still attends meetings at Columbia University and lectures occasionally to select audiences. It turned out that Dr. Chess knew little about Neubauer's work. In fact, when we met she didn't know whether he and Viola Bernard were still alive. It seems that even though they were colleagues working in the same city they were not close.

Chess believes that twins have a right to know that they are twins. Nevertheless, she defended Neubauer's decision to keep this information from the twins' adoptive families - after all, this knowledge had been entrusted to him. 'He was being discreet', she said. Interestingly, Chess had adopted her two eldest children and had given birth to her two youngest. Consistent with the views of the 1950 s and 1960 s, she said that she had never wanted to learn about her adoptive children's pasts because 'they are my children'. When I mentioned Viola Bernard, Chess remembered that Bernard had regarded Chess as her protégé. Apparently, Bernard had tried hard to involve Chess in some adoption work (not at the Louise Wise Services), but her efforts did not pay off. Chess recalled, 'She [Viola Bernard] treated me as her protégé, but I wasn't'. She also recalled that Bernard had thought of herself as a 'psychiatric busybody'.

According to Dr. Chess, the single reared-apart $M Z$ twin pair in the NYSLS was found serendipitously. Sophie Ladimer, one of Chess's assistants, was visiting her pediatrician's office and noticed a photograph of a beautiful baby girl. The doctor mentioned that it was not his child, but was a member of an MZ twin pair that he had helped to separately place. Ladimer was interested in the case from a scientific point of view and received permission to contact the two adoptive families. Soon, the twins were part of the NYSLS and were studied by the researchers until they turned 16. They had a Parent Traplike meeting. Twin A (who did not know she was a twin) attended summer camp when she was 12 or 13 years old. A girl there seemed surprised to see her and called her by the wrong name. It was a case of mistaken identity - the girl had been friendly with Twin B (who was aware that she was a twin). One day after camp had ended the telephone rang in Twin A's home. Her mother answered - it was her daughter's twin (Twin B). When the mother told her daughter who had called, the girl cried and accused her mother of lacking the confidence in her to tell her she was a twin. Eventually, the twins met and became close for a while. Chess recalls that the twins had many similarities — interests in music and gymnastics, average skills on the Information and Similarities subscales of the WISC, and elevated scores in creativity.

Chess received written permission from the twins' families to write up their research for publication, but never did so. She explained to me that one twin's father was concerned that someone would recognize his family from the report - even though he himself had spoken to many people about raising a separated twin. I asked Dr. Chess if she intended to ever write up the data. She said no and indicated that she might not even have the material anymore. But when I was ready to leave two hours later she said to call her in a few weeks - perhaps she would write it up after all. This seemed reasonable to me because the families knew that they had adopted twins and were informed participants in her studies. Chess had even obtained consent to present her findings as a case report. However, she had promised the family that she would not publish them once their privacy concerns were known. I called her in March 2005 to obtain her final decision - she has decided against publishing, citing her earlier promise not to. She added that it was 'just one small story', but clearly acknowledged its interest and importance. This clarified why the paper in progress by Chess, Ladimer and Thomas never went to press.

\section{$\overline{\text { Closing (but not Final) }}$ Thoughts}

Neubauer's twin data are clearly unique, the only existing data on separated twins to have been gathered prospectively. A key question is whether or not to publish the findings in the event that one can gain early access to the Columbia University and Yale Child Study Center materials that are sealed until 2066. Among the issues this would raise are: Would potentially new findings emerge, and would analysis and publication by current investigators condone or excuse the fact that important life history information was concealed from the participants?

New findings would emerge in the sense that prospective longitudinal data (e.g., IQ scores, physical measures, parental reports) on separated MZ twins would be available for the first time. However, it is unlikely that the findings would really be 'new' or would significantly change current thinking on genetic and environmental influences on development. In other words, it is likely that the MZ twin children would show synchronized patterns of behavioral and physical development, outcomes that would be explained with reference to their identical genetic make-up, as in the 1986 case study and in other published works (e.g., Wilson, 1983). Thus, the findings would probably not be new, in and of themselves, but they would offer a new way of confirming what is known.

Inspection of the CDC twin data might yield new ideas about how experience affects development. It may be that co-twin differences could be tied to specific features of the twins' rearing environments more directly and more accurately than has been possible with available data. Such analyses have been conducted with young twins reared together (Reiss at al., 2000), but not with young twins reared apart. Given that only 13 families were involved in the CDC study (five twin sets and one triplet set), it is unlikely that firm conclusions regarding associations among parental rearing practices, childhood experiences and behavioral 
outcomes could be drawn. But new hypotheses may be generated.

I have generally maintained that arguments in favor of publishing questionable data would be acceptable if the data helped save a life or uniquely benefited some individuals or groups. However, the CDC study data do not meet these criteria. The twins and their families were not hurt physically, but some were hurt psychologically and still suffer, which should not be dismissed or taken lightly. A concern is that publishing the data would send an inappropriate message to current and future investigators, namely that gathering information under misleading conditions is 'okay' because even if the data could not be used at the time of collection they could be used in the

\section{References}

Abrams, S. (1986). Disposition and the environment. In P. B. Neubauer \& A. J. Solnit (Eds.), Psychoanalytic study of the child (pp. 41-60). New Haven, CT: Yale University Press.

Aldridge, M. N., \& Cautley, O. (1976). Placing siblings in the same foster home. Child Welfare, 55, 85-93.

Associated Press. (1980, September 24). Separated at birth, 19-year-old triplets reunited. The Record, p. D28.

Bouchard, T. J., Jr. (1983). Do environmental similarities explain the similarity in intelligence of identical twins reared apart? Intelligence, 7 , 175-184.

Bouchard, T. J., Jr. (1997). IQ similarity in twins reared apart: Findings and responses to critics. In R. J. Sternberg, $\&$ E. L. Grigorenko (Eds.), Intelligence, heredity and environment (pp. 126-160) New York: Cambridge University Press.

Chess, S., Ladimer, S., \& Thomas, A. (in preparation). Behavioral development of a pair of identical twins separated at birth. NOTE: This paper, cited in Thomas, A., \& Chess, S. (1986). Temperament and development. New York: Brunner/Mazel, was not published (Chess, personal correspondence, 2005).

Cummings, J. (1980, September 23). The case of the long-lost brothers, cont. New York Times, 130, p. C10. future. One way to handle this would be to preface publications with a note explaining the origins of the study, in what ways the data collection procedures were inappropriate, and why such practices should be avoided in the future. The papers could then be used as educational examples of how not to study twins and families.

We really do not need the data to be analyzed and published to make this point; writing about the study and discussing it with students and colleagues should be enough. However, some participants may favor publication to justify their separation from their twin, to call attention to the study, or for various other reasons. It may be possible to consult the twins and their families before making a decision to

Cummings, J., \& Krebs, A. (September 19, 1980). Mistaken identity leads to a surprising discovery. New York Times, 130, p. A17.

Johnson, P. I. (1997, May/June). Artificial twinning: An instant family at what price? Adoptive Families, 20-23.

Juel-Nielsen, N. (1966). Individual and environment: Monozygotic twins reared apart. New York: International Universities Press.

Kendler, K. S., Martin, N. G., Heath, A. C., \& Eaves, L. J. (1995). Self-report psychiatric symptoms in twins and their non-twin relatives: Are twins different? American Journal of Medical Genetics (Neuropsychiatric Genetics), 60, 588-591.

Moilanen, I., Linna, S.-L., Ebeling, H., Kumpulainen, K., Tamminen, T., Piha, J., \& Almqvist, F. (1999). Are twins' behavioral/emotional problems different from singletons? European Journal of Child and Adolescent Psychiatry, 8, 62-67.

National Adoption Information Clearing House (2004). The sibling bond: Its importance in foster care and adoptive placement. Retrieved from Adoption Online site: http://www.adoptions. com/aecsibling.cfm

Neubauer, P. B., \& Neubauer, A. (1990). Nature's thumbprint: The new genetics of personality. New York: AddisonWesley.

Newman, H. H., Freeman, F. N., \& Holzinger, K. J. (1937). Twins: A publish the material. This may be one way to begin to compensate the twins for their lost years together.

It is curious that Bernard's files have been sealed until 2021 and the twin study data have been sealed until 2066. Neubauer said that this was done to protect the twins. But the twins are now adults and able to decide for themselves whether they want to see their files. Researchers today often make project information available to participants with their written consent. I wonder who will seek access to the data when it becomes available years from now. Perhaps someone will try to inspect the material before that. I wonder who is being protected by waiting so long.

study of heredity and environment. Chicago, IL: University of Chicago Press.

Reiss, D., Neiderhauser, J. M., Hetherington, E. M., \& Plomin, R. (2000). The relationship code: Deciphering genetic and social patterns in adolescent development. Cambridge, MA: Harvard University Press.

Saul, S. (1997, October 12). In the name of research. Newsday, 58, pp. A5, A48-49.

Segal, N. L. (2000). Entwined lives: Twins and what they tell us about human behavior. New York: Plume.

Segal, N. L., Hershberger, N. L., \& Arad, S. (2003). Meeting one's twin: Perceived social closeness and familiarity. Evolutionary Psychology, 1, 70-95.

Shields, J. (1962). Monozygotic twins: Brought up apart and brought up together. London: Oxford University Press.

Staff of manuscripts and archives (2004). Preliminary guide to the Jewish Board of Family and Children's Services adoption study records: Manuscript 1585. New Haven, CT: Yale University Library. Available at http://mssa.library. yale.edu/findaids/stream.php? $x$ mlfile= mssa.ms.1585.xml

Staff, I., \& Fein, E. (1992). Together or separate: A study of siblings in foster care. Child Welfare, 71, 257-270.

Taffel, S. M. (1995). Demographic trends in twin births: USA. In L. G. Keith, 
E. Papiernik, D. M. Keith, \& B. Luke (Eds.), Multiple pregnancy: Epidemiology, gestation and perinatal outcome (pp. 133-143). New York: Parthenon.

Taylor, H. F. (1980). The IQ game: A methodological inquiry into the heredity environment controversy. New Brunswick, NJ: Rutgers University Press.
Thomas, A., \& Chess, A. (1977). Temperament and development. New York: Bruner/Mazel.

Wilson, R. S. (1983). The Louisville Twin Study: Developmental synchronies in behavior. Child Development, 54 , 298-316.
Wilson, R. S., \& Matheny, A. (1986). Behavior-genetics research in infant temperament: The Louisville Twin Study. In R. Plomin, \& J. Dunn (Eds.), The study of temperament: Changes, continuities and challenges (pp. 81-97). Hillsdale, NJ: Lawrence Erlbaum Associates. 